\title{
Nanotechnology Trends in Fashion and Textile Engineering
}

\author{
Srinivasan K, Rajanikumar K, Sheetal Bhardwaj K, Lalitha Kumari B and Murthy Chavali* \\ Aarshadhaatu Green Nanotechnologies India Pvt. Ltd., Syamala Nagar, Guntur 522006 Andhra Pradesh, India \\ Submission: December 20, 2017; Published: January 29, 2018 \\ *Corresponding author: Murthy Chavali, Aarshadhaatu Green Nanotechnologies India Pvt. Ltd., Syamala Nagar, Guntur 522006 Andhra Pradesh, \\ India, Email: chavalim@gmail.com
}

\section{Introduction}

Nanotechnology is a growing interdisciplinary technology often seen as a new industrial revolution. It is offering a novel means of processing fabric that could transform the clothing industry. The expectations of modern day consumers regarding the textile products they use have increased dramatically; consumers want textiles that suit their taste and are comfortable, hygienic and eco-friendly. The ever-increasing demand for sophisticated fabrics with special features and exceptional comfort drives the need for the use of nanotechnology in this industry. It is now a very important parameter for the textile industries to reconsider the technologies and chemicals used towards the rich group, so that they can satisfy environmental and consumer requirements. There comes nanotechnology, which brings extremely promising and significant developments for textile industries. Nano-textiles is an emerging and interesting application of nanotechnology. It involves dealing with nano fibers at the atomic and molecular levels in order to tweak their properties. For example, Nano-Tex, a leading company in the field, has developed processes that make traditional cotton and silk fabrics resistant to spills that would normally ruin clothing. Fashion and technology are an astonishing and will inevitably intermingle into one another. The biggest technologists like Apple, Google, and Amazon are curious to create their own path into the world of fashion; however, the interest is mutual. For example, Apple Company is so consistent in doing fancy wearable smart tech like watches; Google hit the market with conductive smart fabrics embedded in a jacket; and Amazon with voice recognition devices and a platform for shopping.

The inclusion of nanotechnology in the textile industry results in next-generation materials with multifunctional properties such as UV protection, anti odour, antimicrobial, antistatic, breathability advanced durability, improved softness, better tear strength, water/spill repellency and wrinkleresistance. It is used to develop desired characteristics in textile materials without disturbing the inherent properties of the textiles including flexibility and washability. Nanotechnology also offers numerous advantages over the conventional process in term of energy saving, economy, eco-friendly, packaging, and control release of the substance. The main applications of nanotechnology in textiles are nano-finishing, nano-chemicals, nano-coating, nanosilver as smart material for textile materials. The most frequently or commonly used nanomaterials incorporated into textile materials are silver, gold, silicon dioxide, titanium dioxide, zinc oxide, aluminium hydroxides, nanoclay, carbon nanotubes, carbon black, graphene, copper, and iron hydroxides. In this communication/opinion we like give our views on nanotechnology trends in fashion and textile engineering.

\section{Nanotechnology in fashion}

To modernize the clothing industry, nanotechnology offers a new approach for the processing of fabric materials. The nanotechnology embedded fabrics can be designed in a way to do almost everything viz; resist liquids, fight off wrinkles, quick drying and breathe. Unlike topical treatments (which wear off eventually), the effect of nanotech in fabrics will be longlasting because the chemicals used in nanotechnology results in a molecular bonding with the fabric materials. By embedding nano-sized particles or fibres with fabric results in an improved fabric properties without significant changes in thickness and weight. For instance, Nano-Tex (a leading nanotechnology company), developed a technology for stain repellent cotton and silk fabrics. Similarly, lightweight water and spills resistant pants were produced by incorporating nano-whiskers into fabrics. Once a material becomes tiny, it begins to perform in different ways [1].

\section{Nanotechnology in textiles}

The conventional methods used in fabrics to impart different properties fails to impart permanent effects and thus leads to losing their functions after wearing or washing/laundering. Consequently, nanotechnology-based textiles or nano textiles gained promising commercial values and are in great increasing demand for the development of sophisticated fabrics with amazing features. Nano-additives can offer higher durability for fabrics because it tweaks their properties in atomic and 
molecular levels. Accordingly, the first generation of nano embedded textiles results in incredible surface properties of fabrics such as water or stain repellence, wrinkle resistance, dirt-free, colour durability, odour-less socks, flame retardancy with enhanced thermal performance and smart clothes that can perform climate control. In addition, these nano-fabrics wear longer between washings and also will not affect the breathability or hand sense [2].

The nanoparticle coated textiles and clothing results in the production of extremely active surfaces for UV-protection and self-cleaning properties. These nanofabrics are also having antimicrobial and antistatic properties through nanometal and metal oxide coatings. The silver (Ag) nano particles possess antimicrobial activity naturally and thus extensively used as coatings in sports clothing to eradicate odours from sweat. Similarly, Zinc oxide ( $\mathrm{ZnO}$ ) nanoparticles incorporated in polymer matrices like soluble starch are used as functional nanostructures for anti-bacterial coatings in inner wears and medical textiles. However, they also cause a great risk to the consumers and the environment as well [3]. As per the study of Rickard Arvidsson on wastewater treatment plant in Gothenburg (Sweden), nanosilver in clothing is found to be largest sources of silver ions in wastewater. They are also found to be injurious to microbes and aquatic organisms even at low concentrations and thus lead to the development of antibiotic-resistant bacteria [4].

\section{Smart textiles}

Smart textiles are defined as fabrics that symbolizes the next generation of textiles likely for use in numerous fashion and technical textile applications. Smart textiles have been developed and designed to fuse technologies (integrated computing power) that can able to sense and react to environmental conditions or stimuli. The incorporation of smart materials and technologies into fabrics paves the way to achieve numerous potential applications such as communication between devices, conduct electricity or energy, sense, react and protect from hazardous environments. Smart textiles are not only for clothing and apparels but also have extended applications in many fields such as robotics, space, automobiles, medicine, aircrafts, surgery and military/defence battlefields which virtually can act as a life saving materials. Smart textiles also used for releasing moisturizer or medication into the skin [5]. Moreover, smart textiles control the body temperature, muscles vibration in athletic activities and can potentially change light and colour in patterns, pictures and video. The recent examples of smart textiles are energy-scavenging fabrics (charged through ordinary body movements), self-powered smart suits (recharged by sunlight), the nano electronic circuit on folded paper and gloves, energy storage textiles (graphene yarns), and graphene-coated 'e-textile' that sense poisonous gases [6].

Waterproofing with Nanotechnology-Researchers from the University of Zurich made this fabric from polyester fibres that are coated with minute silicone filaments. Swiss chemists have developed a water proof nano-fabric that does not get wet, it was also claimed to be the fabric which is the most waterrepellent clothing material available in the market to date. Actually, it revolves around the idea that has been taken from naturally water-repellant surfaces such as lotus leaves, which have a similar combination of tiny nanostructures and (super) hydrophobic substances.

\section{Intelligent textiles}

Intelligent textiles are capable of think for themselves and act accordingly. For example, it will keep us warm in wintry environments or chill in hot environments in our normal day today activities. It is not only confined to the clothing sector, it can be used in protection and safety applications. The most significant examples of intelligent textiles materials are:

a. Phase Change Materials (PCM).

b. Shape Memory Materials (SMM) /wrinkle free materials.

c. Chromic materials (Colour change).

d. Conductive materials and

e. Electronics incorporated textiles.

\section{Wearable textiles}

Wearable textiles are the combination of sensors and small flexible light emitting displays. It enables the warning signal (displayed or sent) as a result of stimuli from the body. The sensors monitor the heart rate, temperature, respiration, and pulse oximetry readings [7]. If signals were below significant values, a wireless communication system automatically could send a distress signal to dial telephones or pager messages in a remote location. For example, Smart Shirt ${ }^{\mathrm{TM}}$ System developed by Sensatex exclusively for the protection of public protection personnel viz; police officers, firefighters, and rescue teams. The health and safety of public safety personnel or victims who trapped in a building and the exact location can be monitored by Smart Shirt ${ }^{\mathrm{TM}}$.

\section{Present status}

As on date, there are around 30 countries in the world are working on innovations and development of nanotechnologybased textiles materials. At present, the application of nanotechnology is in sportswear and spacesuits become one of the greatest emergent segments [8]. The most popular application of nanotechnology in textile is sharkskin suit based on a plasma layer enhanced technology. Speedo's Fastskin ${ }^{\circledR}$ swimsuit was developed by means of V-shaped fibres which imitate the ridges present on the skin of a shark and it helps a trouble-free gliding through the water. Similarly, nanomaterial functionalized textiles are developed specifically to protect exposure from UV radiation, anti-allergenic, absorbent and antimicrobial products used in medical health applications. The moisture management systems incorporated fabrics are used 
for swift evaporation of sweat, reflective textiles, insulations and resilience fabrics for water-based activities. Nano-textiles are also used in the healthcare industry in the form of smart surgical gloves and gowns. Clima Ware developed a fabric material which turns into a personal climate control systems (personal ACs or heaters in shoes, jackets, and helmets) by incorporating nanotechnology.

\section{Anti-bacterial/Anti-microbial fabrics}

The microorganism's growth on fabric causes a range of unwanted effects, not only on the fabric itself, but also on the user. These effects include the generation of unpleasant odor, reduction in mechanical strength, stains and discoloration and an increased likelihood of user contamination. Microbial contamination is a great concern, mainly for textiles used in hospitals as medical devices or for health and hygienic care, but also in sports clothing, water purification systems, animal feed and the food industry. The infections acquired in hospitals may be caused by several bacterial/microbial species, such as Pseudomonas aeruginosa, Escherichia coli, Klebsiella pneumonia, and Acinetobacter baumannii. Therefore consumers are becoming increasingly aware of the implications on personal hygiene and the health risks associated with some microorganisms, the demand for antimicrobial textiles has presented a big increase over the last few years.

Aloevera is an important biomaterial extracts are commonly used in cosmetics. It also possesses antimicrobial properties, especially against gram-positive bacteria. A textile specimen fabric treated with aloevera showed antimicrobial activity that could withstand even after several washings. Extracts from Ricinus communis, S. auriculata and Euphorbia hirta in the ratio of 1:3:2 showed excellent antibacterial activity. Meconopsis napaulensis D.C. leaves were used to dye cotton fabric to impart antifungal properties with activity over $75 \%$ for Alternaria brassicicola and Leptosphaerulin trifoli fungi and $46 \%$ antifungal activity against Trichodermasp. Senna auriculata and Achyranthes aspera are used to finish cotton fabric to impart antibacterial properties. Dystar Auxiliaries developed a textile finishing agent comprising set of vitamins, aloevera and jojoba oil in a silicon matrix for UV protection [9].

\section{Future Trends and Outlook}

Future trends of nanotechnologies in textiles and fabrics will be in two ways. Firstly, the advancement of existing characteristics and their performances in textile materials. Second, development of smart and intelligent textiles materials with extraordinary functions [10]. In future, advertisements, the music and phone calls can be managed seamlessly with the help of control panel placed externally on your sleeve. Similarly, one-touch phone control panel and one-touch iPod control panel connected jacket and the phone will be used for controlling the voice calling (caller ID features) and music (track controls) with an LCD panel present in the sleeve. Some new functions with textiles to be developed may include, a. Wearable energy storage devices and solar cell.

b. Wound healing and healthcare systems.

c. Sensing abilities and information transferring technology.

d. Self-cleaning and self-repairing functionalities etc.

e. Sophisticated and diverse protection.

There is no doubt that nanotechnology holds enormous opportunities and will break through into every area of textile industry in the next few years.

In the last few years, the customers desire for comfort, hygiene and well-being, concerning odor control and microorganisms protection, has created a large and rapidly increasing market for the expansion of antimicrobial textiles. Presently, industries are trying to adopt advanced technologies and increase the use of sustainable materials for manufacturing processes. Research working for the above parameters too nanotechnology in fashion and textiles to improve and categorize as Smart Textiles, Intelligent Textiles, Wearable Textiles, Anti-bacterial/ anti-microbial fabrics. Application of nanotechnology and other technologies in textile finishing will certainly show promising outcomes and can also reduce the consumption of chemicals, energy and water [11].

The application of plant extracts in textile finishing has a wide scope in healthcare textiles. The textile industry is currently not operating in an entirely eco-friendly and sustainable manner; however, there are numerous methods utilizing nanotechnology ways some parameters can be improved. Integration of modern chemistry principles, physical methodologies and advanced technologies may play a major role in developing smart, intelligent and wearable textiles.

\section{References}

1. Gao Y, Cranston R (2008) Recent advances in antimicrobial treatments of textiles. Text Res J 78(1): 60-72.

2. Zanoaga M, Tanasa F (2014) Antimicrobial reagents as functional finishing for textiles intended for biomedical applications. I. Synthetic organic compounds. Chem J Mold 9(1): 14-32.

3. Shahidi S, Wiener J (2012) Antimicrobial Agents-Chapter 19: Antibacterial Agents in Textile Industry. In Tech: Rijeka, Crotia.

4. Matsunaga T, Tomoda R, Nakajima T, Wake H (1985) FEMS Microbiol Lett 29: 211.

5. Potiyaraj P, Kumlangdudsana P, Dubas ST (2007) Synthesis of silver chloride nanocrystal on silk fibers. Materials Letters 61: 2464-2466.

6. Bajpai D, Vankar PS (2007) Antifungal textile dyeing with Mahonia napaulensis D.C. leaves extract based on its antifungal activity. Fibers Polym 8: 487.

7. Joshi M, Ali SW, Rajendran S (2007) Antibacterial finishing of polyester/ cotton blend fabrics using neem (Azadirachta indica): A natural bioactive agent. J Appl Polym Sci 106(2): 793-800.

8. Chandrasekar S, Vijayakumar S, Rajendran R (2014) Application of chitosan and herbal nanocomposites to develop antibacterial medical textile. Biomed Aging Pathol 4(1): 59-64. 
9. Sathianarayanan MP, Bhat NV, Kokate SS, Walunj VE (2010) Antibacterial finish for cotton fabric from herbal products. Indian J Fiber Text Res 35: 50-55.

10. Montazer M, Alimohammadi F, Shamei A, Rahimi MK (2012) In situ synthesis of nano silver on cotton using Tollens' reagent. Carbohydrate Polymers 87(2): 1706-1712.
11. Varghese J, Tumkur VK, Ballal V, Bhat GS (2013) Antimicrobial effect of AnacardiumOccidentale leaf extract against pathogens causing periodontal disease. Adv Biosci Biotechnol 4: 15-18.

Your next submission with Juniper Publishers will reach you the below assets

- Quality Editorial service

- Swift Peer Review

- Reprints availability

- E-prints Service

- Manuscript Podcast for convenient understanding

- Global attainment for your research

- Manuscript accessibility in different formats ( Pdf, E-pub, Full Text, Audio)

- Unceasing customer service

Track the below URL for one-step submission https://juniperpublishers.com/online-submission.php 